\title{
LINGUISTIC ERROR CORRECTION OF JAPANESE SENTENCES
}

Tsutomu Kawada, Shin-ya Amano and Kunio Sakai

Information Systems Lab., Research and Development Center, Toshiba Corporation

1 Komukai Toshiba-cho, Saiwai-ku, Kawasaki 210, JAPAN

\section{Abstract}

This paper describes a newly developed linguistic error correction system, which can correct errors and rejections of Japanese sentences by using linguistic knowledge.

Conventional optical character readers (OCR) need human assistance to correct their recognition errors and rejections. An operator must teach the OCR correct answers whenever an illegible character pattern occurs. If this error correction operation is mechanized, the throughput of the OCR will increase.

This linguistic error correction system offers means of automated error correction by analysing sentences of the OCR outputs linguistically. This system grammatically selects legal letters from the candidates which can not be decided uniquely by pattern recognition only, and recommends grammatically and semantically meaningful letters for the illegible letter.

\section{Introduction}

More than 2,000 different chinese characters are used in Japanese newspapers and publications. The large repertory of letters as well as the structual complexity of each character pattern are the main difficulties to recognize letters by OCR. Mutually similar character patterns mainly cause recognition errors and rejections. The difference between such similar letters usually concentrate on a local area [ 滅 ……減，徍 .... 微，億……憶 etcl. The output of 'oCR contains these ambiguities.

It is necessary to use the contextual information contained in every kind of natural text. The application of context makes it possible to detect errors or even to correct them. The main object of this error correction system is to resolve these ambiguities on the basis of linguistic knowledge. To resolve these ambiguities each ambiguous letter is put in its sentence, and the sentence is analyzed syntactically and semantically. When the sentences is acceptable the letter is selected preferably.

There has been some contextual post processing systems. 1 2 But these systems are designed to read only postal-addresses. The words which are included in the postal-address are restricted within a relatively narrow do- main. The postal address usually consists of a person's name, place name, postal code and numbers. On the other hand this newly developed kanji OCR can read actual texts of Japanese sentences, and its contextual error correction system of it has been designed to deal with many kinds of words of various parts of speech (noun, verb, adjective, adverb, pronoun, etc.). This error correction system has a practical 25,000 words dictionary, and can correct 53.8 percent of the errors which are included in the outputs of kanji OCR.

\section{Restrictions}

This system imposes two restrictions on input data. One is that the input must consist of grammatical Japanese sentences in order that syntax analysis can be applicable. This system is not effective for only numeral data texts or a mere list of words.

The other restriction is that the texts to be dealt with must be limited to a special field. By this restriction we can limit the number of terminologies which are used in the field.

The corpus used for the experiment is 1,700 claims of patent gazettes of the Japan Patent office. These gazettes concern the manufacturing technology of LSI devices for thirteen years $(1964-1976)$. Figure I shows an example of them. This corpus includes 306,000 words. There are about 5 thousand different words in it. The distribution of the various categories are as follows;

$\begin{array}{lrlr}\text { noun } & 3603 & \text { functional word } & 90 \\ \text { verb } & 832 & \text { suffix and prefix } & 110 \\ \text { adjective } & 75 & & \\ \text { adverb } & 61 & & \\ \text { conjunction } & 30 & & \end{array}$

As twenty thousand common words are added to these words, the dictionary contains about twenty-five thousand words.

\section{Features of Patent Sentences}

A Japanese written language consists of kanji, kana (hirakana and katakana) and alphanumeric letters. Kana is a phonetic symbol and kanji is an ideograph. The kana set (either hiragana on katakana) consists of 48 letters. More than 2,000 different kanji letters are daily used.

Japanese people write a sentence like one 
(54) M O S 型半尊体集棈回路新㥀

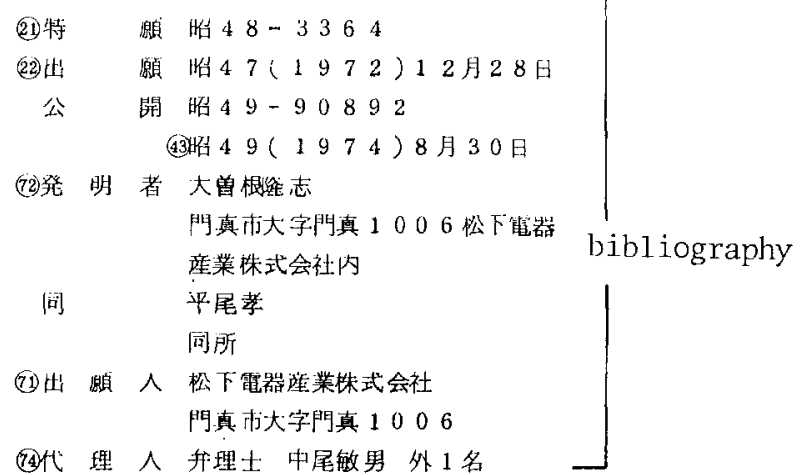

\section{(57)特許声求の部闻}

1 半尊体基板闪飞形成さ九たンース、ドレイン 拡散領域かよびてれらの領城間に設置されたグー

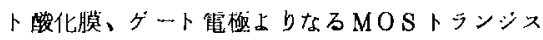
タと、このM OSトランシスタ上に形成されを唐 比热抗の多絬晶シリコン層と、上記多結晶シリコ ン看の一部に不絈物を泩人して形成されるとと。

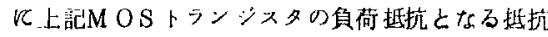
体とを傅えたととを特徵とするMOS型半尊体集 積问路挔置。

Figure 1. Actual Patent Gazette

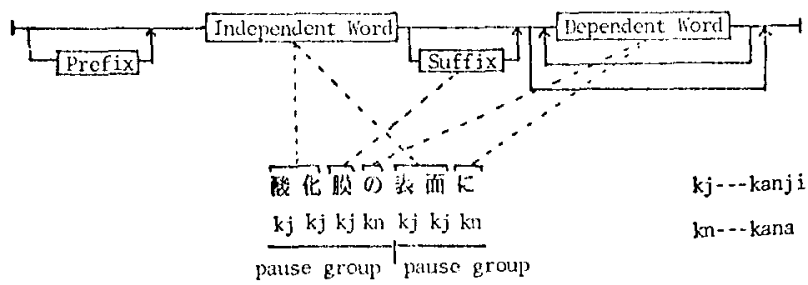

Figure 2. Construction of a Pause Group.

continuous string of letters with no space (see Fig. 1). Japanese is different from western languages in this point. It is firstly important to identify words in the continuous string of letters to analyze a Japanese sentence. Figure 2 shows the construction of a pause group which is the minimum meaningful unit of a Japanese sentence. The prefix, the independent word and the suffix are usually written in kanji or katakana letters. The dependent word is written in kana letters. Changes of letter types as well as punctuation symbols give us useful clues to the boundaries where it is possible to separate a long letter string into shorter manageable units (pause group). This correction sys- tem detects words by using such conditions for these boundaries (Fig. 2).

Experiments were conducted for the clajm sentences of the patents. A claim sentence has a particular style. Most of the claim sentences consist of one sentence. An analytical study 3 of the claim sentences showed that all sentences were categorized into 14 sentence patterns by coordinate phrases. The average count of words for a sentence is 180 words. The sentence is a big noun phrase and is constructed from many coordinate adjective or adverbial phrases which modify the same word. The claim sentence is so long that it is practical to analyze it on the basis of these phrases.

\section{Kanji OCR and it's Errors}

The large number of character categories as well as structual complexity of each character pattern are the dominant difficulties in kanji character recognition. A two-stage recognition method 4 has been developed to cope with these difficulties. This method employs an efficient candidate selection prior to a precise individual recognition. Fig. 3 shows a diagram of the two-stage recognition method.

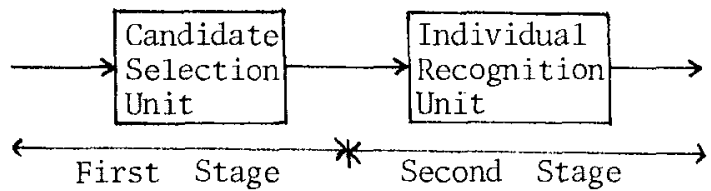

Figure 3. Two-Stage Recognition Method Diagram

In the first recognition process stage, feature extraction is carried out on the input pattern. Candidate characters are obtained according to their geometrical features. In the second stage, pattern matchings are carried out between the input pattern and each reference pattern in selected candidate characters. The decisjon is made on the basis of their similarity values.

The mutually similar patterns as well as low print quality cause recognition errors and rejections. These illegible letters have low similarity values. The recognition speed of this kanji OCR is 100 characters per second. More than 99 percent correct recognition rate was obtained for actual data. The average letter count of the claim sentences is 450 letters. Consequently this system encounters an illegible letter every second and three or four letters in a claim sentence.

As the illegible letters have low similar- 
ity values, this correction system can find doubtful letters easily. If this error correction system checks all letters which are contained in a text, it needs much time to process. This error correction system picks out only the phrases which contain illegible letters, and analyze the grammatical legality of them. By this restriction this error correction system decreases the processing time and becomes a practical one.

\section{Error Correction Method}

The error correction system has three analysis functions (Fig. 4).

a) word analysis function

b) syntax analysis function

c) wording analysis function

Two notations are used here. When one letter can not be recognized uniquely, the candidates for the letter are enclosed in parentheses. A letter which can not be recognized at all is expressed by a question mark.

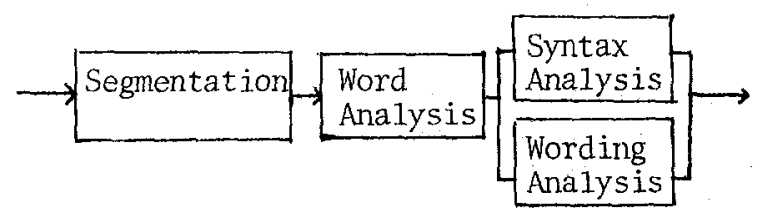

Figure 4. Error Correction Method Diagram

\subsection{Word Analysis Function}

In case of encountering an amriguous letter in a sentence, the word analysis program searches the dictionary to find a grammatically and semantically valid candidate.

For example, '[ハハバ]多ーン認識

([PA BA] TANNINSIKI)' shows that the first letter is an ambiguous letter. In this case, two candidates are tested. A candidate ' パタ-ン

㒛識 (pattern recognition)' is meaningful

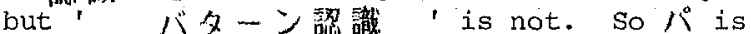
determined as the unique answer.

Some Japanese letters resemble closely.

Example 1. Letter Meaning

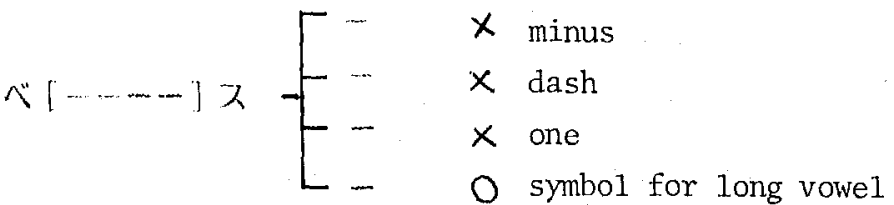

The selection from these resembling patterns depends on their context. I- (a long vowe 1)' is reasonable for $\bigwedge^{[----]}$入 (BEESU, base).
Two or more words are frequently connected without any conjunction or preposition in Japanese sentences. In this case the word analysis program calls the compound word analysis subprogram which looks up the word dictionary and makes a compound word from two or three words to analyze it. The above example is a compound word. ' パターン諗識 (pattern Recognition)' is a compound word constructed from '

パターン (pattern)' and ' 諰傤 (recognition)'. This subprogram has not only a full-string but a sub-string matching ability (Fig, 5).

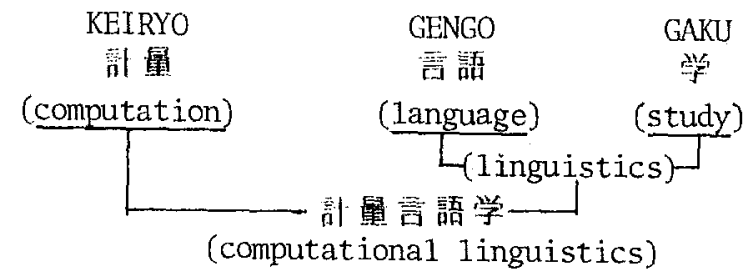

Figure 5. Sub-string Matching of a Compound Word

When a letter has no candidate letter, the word analysis program consults the dictionary and searches for words which fill up the illegible letter.

Example 2

\begin{tabular}{|c|c|c|}
\hline - & $\begin{array}{l}\text { inovation } \\
\text { proof }\end{array}$ & $\begin{array}{l}\text { noun, verb } \\
\text { noun, verb }\end{array}$ \\
\hline - 表明 & manifestation & noun,verb \\
\hline 辛明 & civilization & noun \\
\hline 照明 & lighting & noun, verb \\
\hline 透明 & transparency & adjective verb \\
\hline 一判明 & become clear & noun, verb \\
\hline
\end{tabular}

In this case seven letters fill up the ?. The selection from these candidates is performed in the next syntax analysis step. This word analysis program is not valid for consecutive illegible letters. As most of the Japanese words are one or two Kanji letters, consecutive illegible letters do not give us any clue to search the dictionary. When we are given consecutive illegible letters '??', we can hardly guess what they are.

\subsection{Syntax Analysis Function}

When the word analysis is unsatisfactory to resolve the ambiguities, the syntax analysis is applied to them. In example 2, there are still seven candidates which were selected by the word analysis function. The syntax analysis program refers the contextual information.

Example 3. ?明な霓極 (transparent termina1)

発、証、表、文、照、判 $x$ 透 
This program first conducts a morphological analysis of the given pause group, and analyzes the syntactic role of each pause group in its phrase. A noun or verb does not conjugate like - 5 (NA), and only an adjective verb can conjugate like ' to (NA)'. So ' 透明 ' is selected uniquely.

Example 4. 基板 [が、か] ある

KABAN (GA KA)ARU 基板がある

There is a base. 基板かある

In this case' 基板 (KIBAN; base)' in a noun, ' ある (ARU; be)' is a verb, 'が (GA)' is a particle to indicate the subject, and ' is a particle to indicate an alternative or question. The particle ' が' only makes the sentence grammatical and' 基板が5ろ ' is the unique answer.

This syntax analysis program performs the morphological analysis to the segmented pause groups (Fig. 2). If the segmentation is incorrect, this program can not analyze the phrase or sentence. So this program retries the segmentation of the input string to make successful analysis results.

Example 5. a) 制御回路に[ぞぞ］れぞれ加え

b) 制御回路に[そぞ］れぞれ/加え

\section{c) 制御回路に/それぞれ/加究} (control circuit) (each) (add)

This example shows the retry process. The segmentation program firstly segments a string at the point of letter type changing (b). This segmentation is not correct. The first pause group is not grammatical. This program assumes that this pause group may be a compound pause group, and searches all possible separations from left to right. This program finds a embedded adverb' Zれ れ 中 (SOREZORE; each)', and by this segmentation this sentence can be analyzed successfully. The other candidate ' $z$ ' can make no grammatical sentence.

\subsection{Wording Analysis Function}

In the sentences of patent gazettes, important words or key words are repeatedly used with anapholic pronouns. This fact is a very important clue to find an anaphola or to guess the ambiguous letter. The arrows in Fig. 6 show the anapholic relations of words in a text. Some kinds of particular anapholic pronouns appear in patent texts (' .t. 'I' (above-mentioned)', ' 该 (GAI; such)', '注 (DOU; same)' and -O (KONO; this)'). When an illegible letter occurs in an anapholic words, the wording analysis program searches the indicated word and correct the illegible letter by the matched letter. In Fig. 6, '昆矿接合? 域
特許請求の筁团

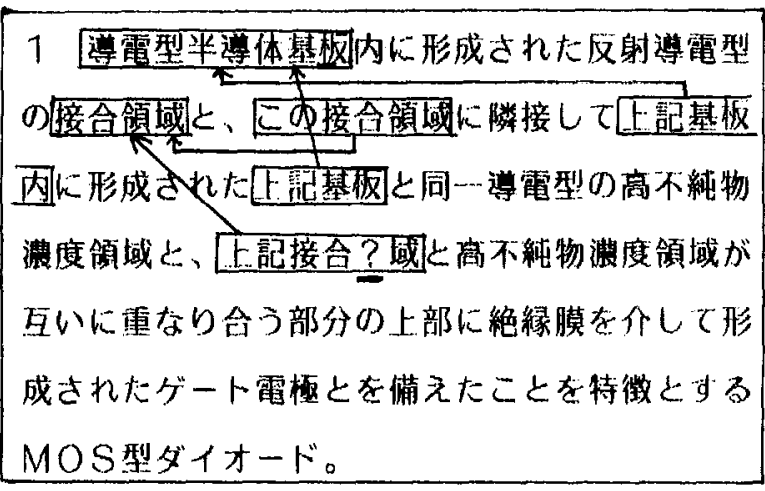

Figure 6. Anapholic Relations in a Sentence

(above-mentioned connected area)' has an anapholic pronoun' 上院'.'接含? 域' is compared with the indicated word! 接合傎域 , and? is corrected to ' 倾 '. The wording analysis program automatically prints out a glossary of texts. This glossary is used to augment the dictionary of the error correction system.

Numeric expressions are also used frequently. Numeric expressions are analyzed by using semantic relations of words in their vicinity. As the bibliography of a patent contains the name of a person, place and affillated organization, the correction system needs to change the dictionary from a common dictionary to a proper noun dictionary. In a proper noun pause group, it is more important to analyze the semantic relation among the words. 5

Example 6 .

(KAWASAKI city

种余川鼠? 㟨速 KANAGAWA prefecture)

KANAGAWA KEN KAWASAKI SHI

$$
\text { -[証崳 it (name of city) }
$$

This phrase describes an address, and ' i†j (city)' is a suffix for the name of a place which does not connect with a person's name. So the illegible letter can be decided uniquely.

\section{System Configuration and Experimental Results}

Fig. 7 shows the kanji OCR and linguistic exror correction system. Fig. 8 shows the configuration of this system. The error correction system is programmed on a mini-computer (TOSBAC40). The text editing terminal is a newly developed Japanese word processor. The operator of this system can confirm the error correction results on the CRT display, change the form of the text by versatile editing functions, store and transfer them to the host machine.

The experimental results for actual 250 


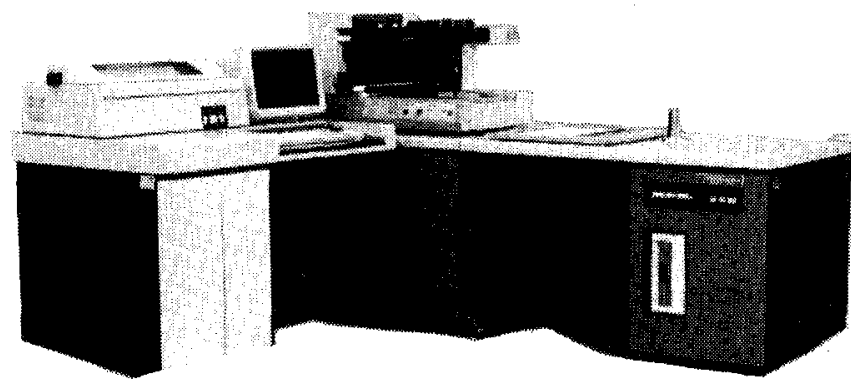

Figure 7. Overal1 View of Error Correction System

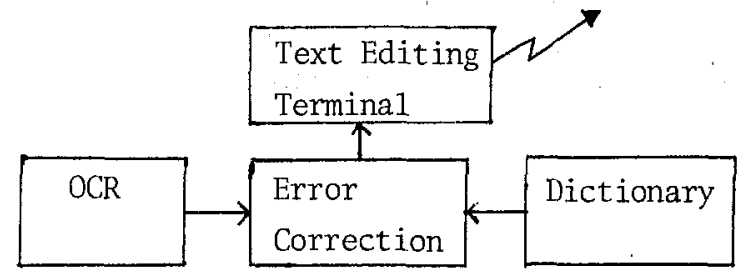

Figure 8. System Configuration

patent texts were as follows;

effective correction ...... 53.8 percent ineffective correction ..... 38.5 percent wrong correction ......... 7.7 percent The ineffective correction rate shows the percentage of letters which this system can not correct.

Example 7. Wrong correction

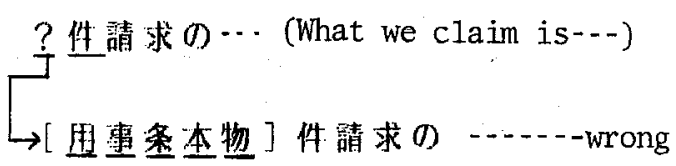

(YOU II JYOU HON BUTU) KEN SEI KYU NO

特許請求 $の$
This example shows a case of wrong correction. The first letter was illegible. And the next letter ' 件 (KEN)' was misread. The correct letter is ' 許 (KYO)'. The kanji 'OCR has made an error. This error correction system tried to correct the ? letter by using ' i i ' ' which was a wrong letter as the clue for correction, and made a wrong correction.

\section{Conclusion}

This error correction system can correct about fifty percent of the errors and rejections of kanji OCR outputs and was effective to increase the total throughput of the kanji OCR.

The kanji OCR reads letters according to their geometrical feature, and this linguistic error correction system reads a sentence according to the linguistic knowledge. The combination of the kanji OCR and linguistic error correction system realizes a practical Japanese text reader and can cope with the increasing demands for input of Japanese document information. The throughput rate of the OCR, combined with this linguistic error correction system, is about 10 times higher than that of a conventional manual data entry.

\section{Acknowledgments}

Parts of the research, and development of the system were made under contract with the Ministry of International Trade and Industry on the Pattern Information Processing System (PIPS) Project.

\section{References}

(1) S. Viresh, "An Approach to Address Identification from Degraded Address Data", Proc. NCC pp. 779-783, 1977.

(2) E. M. Riseman, A. R. Hanson, "A contextual Postprocessing System for Error Correction Using Binary n-Grams", Trans. On COMPUTER IEEE, Vol. C-23, No.5, MAY, pp.480-493, 1974.

(3) H. Saiito, M. Noyori, "Patterns of Claim of Japanese Patent Sentences" computational linguistics, IPSJ, pp.1-10, Feb. 1978.

(4) K. Sakai, S. Hirai, T. Kawada and S. Amano, "An Optical Chinese Character Reader", Proc. Third IJCPR, pp.122-126, 1976.

(5) T. Kawada, S. Amano, K. Mori and K. Kodama, "Japanese Word Processor JW-10", Proc. COMPCON'79, pp.238-242, sept. 1979. 